\title{
The organization for collecting forest mushrooms in Finland
}

\author{
UOLEVI MILDH
}

\begin{abstract}
MILDH, U. 1978: The organization for collecting forest mushrooms in Finland. - Karstenla 18 (suppl.).

The yearly mushroom crop and the education of mushroom consultants and harvesters in Finland has been discussed. In order to be able to utilize the enormous natural resources available in mushrooms trained persons are considered necessary. Training is carried out through cources of different length. The aim is that all the commercial mushrooms are through cources of different
harvested by trained persons.
\end{abstract}

U. Mildh, Dairies' Association, Valio, Finnish Co-operative, Kalevankatu 61, SF-00180 Helsinki 18, Finland.

The annual mushroom yield in Finland is estimated to be 100-300 kg per forest hectare (Rautavaara 1947, Ohenoja 1968-1977). As there are 19 mill. hectares of forestland in our country, the yield of mushroom per single growth period is, even according to the lowest estimate, $1900 \mathrm{mill} . \mathrm{kg}$. The proportion of edible mushrooms is about $50 \%$ of this quantity that is 950 mill. $\mathrm{kg}$. Taking into consideration that about $70 \%$ of the mushrooms are contaminated by larvae and therefore unsuitable for human food, the amount of edible mushrooms left for collection is, even in a poor crop year, about $285 \mathrm{mill}$. $\mathrm{kg}$.

In order to utilize these significant natural resources, the Department of Forestry started to train mushroom consultants and harvesters in 1969. Later the training was transferred to the forestry education department of the National Board of the Vocational Education, which is the present central organ of the organization.

Courses for mushroom consultants have nowadays been centralized at four forestry education institutes, which function at the same time as contacting centers for the mushroom consultants in their own district. During recent years one basic course and one continuation course have been arranged every year at each institute, that is totally 4 basic and 4 continuation courses for the whole country. Each course consists of 20-30 pupils who are selected on the basis of applications.

The duration of the course is one week and is mainly based on group work. In this way teaching is made individually, corresponding to everybody's knowledge. In the first days of the course, the consultant candidates learn to recognize, classify and deal with our most important commercial mushrooms (the 30 species of the most general and high-yielding mushrooms), their "imitators" (those mushroom species that most resemble the abovementioned ones), and the poisonous mushroom species in our country. The second half of the week is dedicated to the training of harvesters, most often in the form of practical training, together with qualified collectors.

At the end of the course there is a test. On passing the test, the mushroom consultant is given a certificate on which are marked those mushroom species with which the person is competent. Further, the consultants may participate in a continuation course, where they can refresh their knowledge, and also take tests on new species of mushrooms.

Training of havvesters is taken care of by the mushroom consultants, each in one's own commune. In a one -day course, atmost three commercial mushroom species are taught at a time. At the end of the course the harvester is given a card with the names of the mushrooms in which one is qualified to collect for commercial purposes.

The object of the training is that each commune obtains at least two mushroom consultants in charge of the training, and that each of these consultants would have a minimum of 30 active trained harvesters. In this way it is possible to ensure a continuous supply of raw material for the vigorously-developing commerce and food industry (Table 1 ).

The mushroom trade in our country is taken care of by both the central organizations and small-scale enterprises. 
Table 1. The number of mushroom consultants and harvesters.

$\begin{array}{lrc}\text { Year } & \text { Consultants } & \text { Harvesters } \\ 1969 & 115 & 230 \\ 1970 & 169 & 1150 \\ 1971 & 229 & 4173 \\ 1972 & 418 & 12176 \\ 1973 & 637 & 18048 \\ 1974 & 781 & 27412 \\ 1975 & 923 & 28466 \\ 1976 & 1063 & 30068 \\ 1977 & 1172 & 35000 \\ 1978 & 1300 & 45000^{*} \\ 1979 & 1400 & 48000^{*} \\ 1980 & 1500 & 50000^{*}\end{array}$

* Goals for future
Nowadays wild mushrooms are mainly bought fresh, most often cleaned and classified, each species being packed separately.

The most significant commercial mushrooms are Gyromitra esculenta, Cantharelius cibarius, Boletus edulis, Lactarius trivialis, Lactarius rufus and Lactarius torminosus. Also small quantities of other mushrooms (for example Albatrelzus ovinus and Cantharellus tubaeformis) are received according to the supply. and demand.

It is our aim that all the commercial mushrooms are harvested by trained persons. In this way we can best ensure the quality as well as the health requirements in marketing mushrooms.

\section{References}

Ohenoja, E. 1968-1977: pers. comm.

Rautavaara, T. 1947: Suomen sienisato. - 534 pp. Porvoo. 